IZA DP No. 5229

Economic Reform, Informal-Formal Sector Linkages and Intervention in the Informal Sector in Developing Countries: A Paradox

Hassan Arvin-Rad

Arnab K. Basu

Maria Willumsen

October 2010 


\title{
Economic Reform, Informal-Formal Sector Linkages and Intervention in the Informal Sector in Developing Countries: A Paradox
}

\author{
Hassan Arvin-Rad \\ University of Illinois-Urbana Champaign \\ Arnab K. Basu \\ College of William and Mary, \\ ZEF and IZA \\ Maria Willumsen \\ Florida International University
}

Discussion Paper No. 5229

October 2010

\author{
IZA \\ P.O. Box 7240 \\ 53072 Bonn \\ Germany \\ Phone: +49-228-3894-0 \\ Fax: +49-228-3894-180 \\ E-mail: iza@iza.org
}

Any opinions expressed here are those of the author(s) and not those of IZA. Research published in this series may include views on policy, but the institute itself takes no institutional policy positions.

The Institute for the Study of Labor (IZA) in Bonn is a local and virtual international research center and a place of communication between science, politics and business. IZA is an independent nonprofit organization supported by Deutsche Post Foundation. The center is associated with the University of Bonn and offers a stimulating research environment through its international network, workshops and conferences, data service, project support, research visits and doctoral program. IZA engages in (i) original and internationally competitive research in all fields of labor economics, (ii) development of policy concepts, and (iii) dissemination of research results and concepts to the interested public.

IZA Discussion Papers often represent preliminary work and are circulated to encourage discussion. Citation of such a paper should account for its provisional character. A revised version may be available directly from the author. 
IZA Discussion Paper No. 5229

October 2010

\section{ABSTRACT \\ Economic Reform, Informal-Formal Sector Linkages and Intervention in the Informal Sector in Developing Countries: A Paradox ${ }^{*}$}

Within a general equilibrium framework of a developing economy with a foreign owned factor of production, this paper questions whether the informal-formal sector relationship is procyclical/ complementary - expansion or contraction in one necessarily implies an expansion or contraction in the other - when the informal sector is subject to a technological shock. We derive a necessary and sufficient condition under which a positive shock to the informal sector results in a contraction in both the size of the urban formal sector and the informal sector. Thus, although our result shows that the informal-formal sector relationship is procyclical, it nevertheless calls into question the conventional wisdom on the benefits of intervention in the informal sector of developing economies, particularly where multinational corporations sub-contract certain labor intensive stages of production to the informal sector.

JEL Classification: J8, R13, R23

Keywords: rural-urban migration, urban informal sector, technological change

Corresponding author:

Arnab K. Basu

Department of Economics

College of William and Mary

131 Morton Hall

Williamsburg, VA 23187

USA

E-mail: akbasu@wm.edu

\footnotetext{
* We thank two anonymous referees for their helpful comments and suggestions. Basu thanks the Alexander von Humboldt Foundation, Germany for research support. The usual disclaimer applies.
} 


\section{Introduction}

Often described alternatively as the 'unorganized sector', 'unregistered economy', 'third economy', 'parallel economy' and the 'shadow economy', amongst others, the urban informal sector has become an integral part of the economic landscape across the developing economies of Africa, Asia and Latin America. According to Chen (2006), informal employment broadly defined comprises one-half to three-quarters of nonagricultural employment in developing countries with $48 \%$ in North Africa; $51 \%$ in Latin America; $65 \%$ in Asia; and $72 \%$ in sub-Saharan Africa $^{1}$. Additionally, informal wage employment in developing countries comprises 30 to 40 per cent of total informal employment (outside of agriculture). Although the origins of the urban informal sector can be traced to the emergence of urban unemployment caused by rural-urban migration and the absence of government support for the unemployed, there is little consensus on the scope and definition of the informal sector (Guha-Khasnobis, Kanbur and Ostrom 2006). The only consensus seems to be that the informal sector encompasses a wide range of activities (production, distribution and employment) and tend to fall outside the purview of the regulated or formal economy (De Soto 1989; Portes, Castells and Benton 1989; Chen 2006).

Amongst sociologists, the structuralist school views the existence of the informal sector as a relatively permanent feature of the modern economy integrated with its lead sectors (Portes, Castells and Benton 1989). The linkages between the informal and the formal sector(s) is established through the latter subcontracting certain labor intensive stages of production to the former. The structuralists further contend that since the informal sector is integrally linked with the formal sectors, given a constant level of state regulation, the informal-formal sector relationship is pro-cyclical or in other words, complementary: expansion or contraction in one necessarily implies an expansion or contraction in the other.

The purpose of this paper is to formalize the informal-formal sector relationship in a general equilibrium framework and check whether this relationship is indeed pro-cyclical when the informal sector is subject to a exogenous shock. We introduce a specific form of intervention

\footnotetext{
${ }^{1}$ Schneider and Klinglmair (2004) use data for the years 1999/2000 and show that the average the size of the informal economy in Africa (in percent of GDP) was $42 \%$ with Zimbabwe (59.4\%), Tanzania (58.3\%), Nigeria (57.9\%), Mozambique (40.3\%), Cote d'Ivoire (39.9\%), Madagascar (39.6\%), Botswana (33.4\%), Cameroon $(32.8 \%)$ and South Africa $(28.4 \%)$ forming the highest to the lowest spectrum. In Asia, the average size of the informal economy was $26 \%$ of official GDP with Thailand $(52.6 \%)$ as the highest and followed by Sri Lanka (44.6\%), Philippines (43.4\%), India (23.1\%), Israel (21.9\%), Taiwan and China (19.6\%), Singapore (13.1\%) and Japan (11.3\%). The average size of informal economy in Latin America was $41 \%$ with the largest informal economy in Bolivia (67.1\%), followed by Panama (64.1\%) and Peru (59.9\%). Argentina (25.4\%) and Chile (19.8\%) had the lowest informal economies in Latin America.
} 
in the informal sector - a positive technological change that increases labor productivity for workers in the informal sector, and analyze whether the informal and the formal sectors expand or contract as a consequence. The reason for focusing on a positive technological change in the informal sector stems from the recent debate on whether governments and NGOs should encourage informal sector workers to adopt newer technologies, have access to vocational schools that enhance labor productivity or even have access to cheaper credit through microfinance programs that improves business operations (see for example, Liimatainen 2002).

In the economics literature, the issue of formal-informal sector linkage opens up an interesting but a relatively unexplored question of how a positive or negative shock originating in one sector is transmitted, and more importantly, how these shocks may impact the lead and the lag sectors of an economy. Two papers in this context are worth noting. First, Marjit (2003) concludes that a contraction of the formal sector due to a trade reform (say, a lowering of the tariff) need not necessarily imply an impoverishment of the workers in the informal economy. In fact, Marjit (2003) shows that informal employment and wages both rise subsequent upon a contraction of the informal sector. The intuition behind Marjit's (2003) result is as follows: even though the informal sector produces an intermediate input for the formal sector, the informal sector itself may have labor and capital intensive sub-segments. While a contraction of the formal sector may lead to a contraction of the capital intensive sub-segment of the informal sector, the labor-intensive sub-segment may well expand thereby creating a higher capacity to absorb labor released by the formal sector. This latter effect may lead to not only higher employment levels but also higher wages in the informal sector. Second, Marjit, Kar and Beladi (2007) show that a trade reform that lowers the price of the formal import-competing sector may lead to an increase in both employment and wages in the informal sector. On the other hand, a trade reform that increases the price of the formal export sector may increase wages but definitely lowers employment in the informal sector ${ }^{2}$.

Our paper can thus be viewed as a contribution to the above literature in the broader context of exploring the channels through which shocks are transmitted between the formal and informal sectors of an economy. However, our model differs from Marjit (2003) and Marjit, Kar and Be-

\footnotetext{
${ }^{2}$ In related papers on Economic Liberalization in developing countries with an informal sector, Chaudhuri and Yabuuchi (2007) analyze the consequences of import tariff reduction and foreign capital inflow on the formal-informal sector wage inequality to show that foreign capital inflow reduces wage inequality between the two sectors while import tariff reduction tends to increase it. Roy (2006) studies the effect of a subsidy to the informal sector that when informal and formal sector outputs are imperfect substitutes of each other. Although Roy studies intervention in the informal sector, the basic framework of our model and the issue of the informal sector producing inputs for the formal sector is distinct from that of Roy's.
} 
ladi (2006) in three important respects: (i) as opposed to tariff reduction in the formal sector, economic reform in this paper is modeled as the presence of a formal multinational sector that sub-contracts intermediate stages of production to the informal sector; (ii) the existence of the informal sector in our economy is in response to rural-urban migration of labor in search of a higher urban formal sector wage rather than a secondary sector in either the urban or the rural areas and (iii) the shock to the economy in our model originates within the informal sector itself in contrast to an external shock to the formal sector.

Specifically, the framework we consider follows the cannonical formulation of the informal sector due to Fields (1975), and its subsequent refinements by Dutta-Chaudhuri (1989) and Chandra and Khan (1993). Additionally, we introduce the presence of foreign capital in one of the formal sectors of the economy à la Chandra and Khan. This latter formulation conforms with the move by developing countries to attract multinationals in the urban areas of an economy which, along with the domestic formal sectors, are known to sub-contract labor intensive stages of production to the informal sector (Portes and Schauffler 1993). Alternative to the "spatial" interpretation of multinationals locating in the urban areas of the economy, our framework can also be interpreted in the "economic" sense in so far as these multinational operations share some common characteristics with that of the urban formal sector in terms of paying a higher mandated wage to workers as well as employing the same inputs as the urban formal sector - domestic capital and the informal sector output in the production process.

In our setting, the informal sector thus pertains to a set of economic enterprises that allows the formal sectors of the economy (foreign capital-owned and domestic urban) to maintain a competitive edge by: (a) reducing direct and indirect costs of production, (b) differentiating production and (c) gaining access to a flexible labor pool. We show that a positive shock to the informal sector paradoxically results in a contraction in the size of the urban formal sectors as well as the informal sector itself. Thus, although our result conforms with the structuralists' view that the informal-formal sector relationship is pro-cyclical, it nevertheless calls into question the conventional wisdom on the benefits of intervention in the informal sector of developing economies, particularly where multinational corporations sub-contract certain labor intensive stages of production to the informal sector.

In the following sections we develop our model and analyze the effect of a positive shock to the informal sector on the factor rewards, employment and the sectoral output levels. 


\section{The Model}

We consider a small open economy (a category under which most developing countries with a large informal sector falls under) with four sectors, the rural, the domestic urban, the urban informal and the foreign capital-owned multinational. In this economy, the urban wage paid by the regulated domestic urban sector and the foreign capital-owned sector, is institutionally fixed at $\bar{w}_{u}$, and is the highest of all the wages in the economy ${ }^{3}$. This distortion in the labor market gives rise to a rural-urban wage differential resulting in the equalization of the expected urban wage to the rural wage in equilibrium ${ }^{4}$. A fraction of the urban labor force gets employed into the urban formal sectors of the economy, i.e the domestic urban and the foreign capital-owned sector, while the rest, i.e., the urban unemployed, gets absorbed into the urban informal sector whose wages are the lowest of all the wages in the economy. Furthermore, the informal sector produces a non-traded intermediate good which is used by the domestic urban sector and the foreign capital-owned sector as an input ${ }^{5}$. To sharpen focus and for analytical purposes, consider the equations which formalize this economy.

The production functions of the four sectors, exhibiting constant returns to scale and diminishing marginal productivity to each factor are:

$$
\begin{aligned}
X_{r} & =F_{r}\left(L_{r}, K_{r}\right) \\
X_{i} & =F_{i}\left(L_{i}, K_{i}\right) \\
X_{u} & =F_{u}\left(L_{u}, K_{u}, X_{i}^{u}\right) \\
X_{e} & =F_{e}\left(L_{e}, K_{e}, X_{i}^{e}, \bar{K}_{f}\right)
\end{aligned}
$$

where $X$ suitably subscripted, denotes the sectoral outputs respectively of the rural (r), informal (i), domestic urban (u) and the foreign capital-owned (e). The supply of foreign capital $\left(K_{f}\right)$ is fixed and restricted only to the foreign capital-owned sector, however domestic capital and labor is freely mobile between the four sectors. Finally, the rural, domestic urban and the foreign capital-owned outputs are internationally traded, and given the small country assumption the prices of these traded products are internationally determined.

\footnotetext{
${ }^{3}$ Such an institutionally set urban wage could be due to minimum wage regulations, labor unions or part of an internationally mandated labor standard enforced by the domestic government.

${ }^{4}$ Along the lines of the Harris-Todaro hypothesis (1970).

${ }^{5} \mathrm{We}$ assume that the domestic urban sector and the foreign capital-owned sector produce differentiated varieties of the same product and as such shares, as a common input, the labor intensive intermediate good produced by the urban informal sector.
} 
The material balance equations are:

$$
\begin{aligned}
L_{e}+L_{u}+L_{r}+L_{i} & =\mathcal{L} \\
K_{e}+K_{u}+L_{r}+K_{i} & =\mathcal{K} \\
X_{i}^{e}+X_{i}^{u} & =X_{i}
\end{aligned}
$$

With the demand for foreign capital equaling its' fixed supply. Further, all four commodities are produced at a positive output-price vector and perfect competition prevails in the economy. Thus, the assumption of perfect competition along with that of constant returns to scale gives the price equals unit cost equations as:

$$
\begin{aligned}
\bar{P}_{r} & =C_{r}\left(w_{r}, R\right) \\
P_{i} & =C_{i}\left(w_{i}, R\right) \\
\bar{P}_{u} & =C_{u}\left(\bar{w}_{u}, R, P_{i}\right) \\
\bar{P}_{e} & =C_{e}\left(\bar{w}_{u}, R, P_{i}, \bar{R}_{f}\right)
\end{aligned}
$$

The wage paid in the foreign capital-owned sector is the same as that paid in the domestic urban sector and $\bar{R}_{f}$, the return to foreign capital, is internationally fixed. The price of the informal sector output is determined within the model by the two urban formal sectors.

Labor market equilibrium condition is given by:

$$
\lambda \bar{w}_{u}+(1-\lambda) w_{i}=w_{r}
$$

where $\lambda$, the probability of employment in the two urban formal sectors (domestic urban and foreign capital-owned) is given by:

$$
\lambda=\frac{L_{u}+L_{e}}{L_{u}+L_{e}+L_{i}}
$$

Note that $\lambda$ is determined solely by equation (12) and hence by international prices.

The specifications of our model is thus complete. We have nineteen equations (including the seven independent marginal productivity equations), nineteen unknowns and eleven parameters (including the four production technologies). The model is decomposable in the sense that factor prices are determined solely by commodity prices independently of factor endowments. To see this, note that the return to domestic capital and the price of the informal sector output is determined by the two urban formal sectors (equation (10) and (11)). Once the return 
to domestic capital and the price of the informal sector output is determined, equation (9) determines the informal sector wage and equation (8) determines the rural wage. With the informal and rural wages determined, equation (12) determines $\lambda$.

\section{Technological Improvement in the Informal Sector}

Consider now the effect of a positive shock to the informal sector on factor rewards, sectoral output levels and on the sectoral employment levels. Such a positive shock could be engendered, as examples, through policy interventions such as vocational schools that improve labor productivity of workers or entrepreneurial skills of managers, or through access to better production technology in the informal sector. Formally, and irrespective of the form of intervention, we capture technological improvement as implying a reduction in the input-output coefficients in the informal sector.

Before proceeding it is instructive to offer the following definition. Note that the two urban formal sectors (domestic urban and foreign capital-owned), apart from using domestic labor and domestic capital directly, also uses these two inputs indirectly through the use of the informal sector output as intermediate inputs. It is thus only natural that the amount of domestic labor and domestic capital used indirectly plays a crucial role in determining the factor intensities of the two urban formal sectors. Further, since there is a labor market distortion, and the subsistence wage of the urban unemployed is endogenized through the informal sector, we need to define the factor intensities of the two urban formal sectors in employment adjusted terms. Therefore,

Definition 1 The urban formal sectors (the domestic urban and the foreign capital-owned sector) are said to be relatively more capital (labor) intensive, in the informal employment adjusted gross sense, than the rural sector if and only if

$$
\operatorname{sign}\left\{(1-\lambda)\left(\frac{x_{i}^{u} K_{i}+K_{u}}{x_{i}^{u} L_{i}}\right)-\frac{K_{r}}{L_{r}}\right\}=\operatorname{sign}\left\{(1-\lambda)\left(\frac{x_{i}^{e} K_{i}+K_{e}}{x_{i}^{e} L_{i}}\right)-\frac{K_{r}}{L_{r}}\right\}>(<) 0 .
$$

where $(1-\lambda)$ is the probability of employment in the informal sector and $x_{i}^{m}=X_{i}^{m} / X_{i}, x^{m} L_{i}$ and $x_{i}^{m} K_{i}+K_{m} ; m=u, e$ are respectively, the proportion of the informal output, the amount of labor used indirectly and the amount of domestic capital used both indirectly and directly, in the production of each of the urban formal sector outputs. Consider therefore,

Proposition 1 Technological improvement and factor rewards: Technological improvement in 
the informal sector leads only to an increase in the informal wage, $w_{i}$, leaving unchanged the price of the informal sector output, the return to domestic capital and the rural wage.

Since the return to domestic capital and the price of the informal sector output is determined by the two urban formal sectors (the domestic urban and the foreign capital-owned sector), technological improvement in the informal sector results only in an increase in the marginal productivity of informal labor and is reflected in the higher informal sector wage. With the price of the rural sector output internationally given and the return to domestic capital unchanged, rural wage remains unaffected.

The next two propositions depend on the relative factor intensities of the two urban formal sectors relative to the rural sector. Assuming that the urban formal sectors are both relatively more capital intensive in the informal employment adjusted gross sense than the rural sector ${ }^{6}$, then,

Proposition 2 Technological improvement in the informal sector and sectoral output levels: Technological improvement in the informal sector leads to a decrease in the output of the domestic urban sector and the informal sector, and an increase in the output of the rural sector if and only if the elasticity of substitution between labor and capital in the informal sector is greater than unity ${ }^{7}$. The output of the foreign capital-owned sector remains unchanged.

Proposition 3 Technological improvement in the informal sector and sectoral employment levels: Technological improvement in the informal sector leads to a decrease in the probability of employment in the formal urban sectors (and therefore increases the probability of employment in the informal sector). Employment decreases in the domestic urban sector and the informal sector and increases in the rural sector if and only if the elasticity of substitution between labor and capital in the informal sector is greater than unity. Employment remains unchanged in the foreign capital-owned sector.

The intuitions behind propositions 2 and 3 are as follows: consider first the equation ${ }^{8}$

$$
\hat{X}_{e}=\hat{K}_{f}-\hat{a}_{K_{f}}
$$

\footnotetext{
${ }^{6}$ Of course, the output effects (and thus the employment effects) in the domestic urban and rural sector and the output effect of the informal sector will be the exact opposite of the following results if we assume that the rural sector was more capital intensive, in the informal employment adjusted gross sense, than the domestic urban sector.

${ }^{7}$ We assume that capital and labor are substitutes in the production of the informal sector output, i.e, $\sigma_{i}>0$.

${ }^{8}$ Follows from the full employment condition $a_{K_{f}} X_{e}=K_{f}$, where $a_{K_{f}}$ is amount of foreign capital required per unit of the foreign capital-owned sector output.
} 
With factor proportions fixed by international prices (by virtue of our small country assumption) and in the absence of technological change or an increase (decrease) in the foreign capital inflow into the foreign capital-owned sector, the output of the foreign capital-owned sector is completely determined once the endowment of foreign capital is known. It is therefore hardly surprising that technological improvement in the informal sector has no effect on the foreign capital-owned sector's output or on its usage of the domestic inputs.

Technological improvement in the informal sector however leads to: 1) an output effect in the informal sector such that every unit of output requires less amounts of labor and capital and 2) a substitution effect in the informal sector such that capital (whose price has remained unchanged) is substituted for labor (whose price has increased). If the elasticity of substitution between capital and labor in the informal sector is greater than unity then, in equilibrium, the increased demand for capital by the informal sector results in an outflow of capital from the domestic urban sector to the informal sector. Given that factor proportions are fixed by international prices in the domestic urban sector, there is a corresponding outflow of labor and a reduction in the use of the intermediate input produced by the informal sector which has the effect of causing a contraction in the size of the domestic urban sector. The reduction in the use of the informal sector output by the domestic urban sector reduces the aggregate demand for the former's output, causing a parallel contraction in the informal sector. Finally, the excess labor and capital released from the urban sectors (formal and informal) is absorbed by the rural sector resulting in an increase in rural output ${ }^{9}$.

Turning to the employment effects, from equation (12) it is clear that with the institutionally set urban wage and the rural wage remaining unchanged, an increase in the informal sector wage leads to a decrease in the probability of employment in the formal urban sectors (domestic urban and foreign capital-owned). This in turn implies an increase in the probability of employment in the informal sector in order to maintain labor market equilibrium. Since factor proportions are fixed by international prices in the foreign capital-owned, the domestic urban

\footnotetext{
${ }^{9} \mathrm{~A}$ logical question that arises at this point is: why is the increased demand for capital by the informal sector not met by an outflow of capital from the rural sector? In that case the informal and the domestic urban sector can both expand at the expense of the rural sector. The reasoning is this: suppose there is an outflow of capital (and therefore labor) from the rural sector leading to the informal sector absorbing a part of this capital and thereby increasing its output. The domestic urban sector would then absorb this increase in the informal sector output (at the unchanged price of latter) and since factor proportions are fixed by international prices in the former, it would also proportionately increase its usage of capital and labor. Since the urban formal sectors are relatively more capital intensive, in the informal employment adjusted gross sense, than the rural sector the amount of capital released by the rural sector would be insufficient to meet this increased demand. Along with excess labor in the urban region the economy would thus be at a disequilibrium.
} 
and the rural sectors ${ }^{10}$, employment in the foreign capital-owned sector remains unchanged, decreases in the domestic urban sector and increases in the rural sector. Employment in the informal sector falls due to the combined effect of (i) the domestic urban sector reducing its demand for the intermediate input and (ii) a concurrent substitution effect (capital for labor) within the informal sector.

The conventional wisdom that a positive shock to the informal sector is beneficial to informal labor in particular, and to the informal sector in general, does not hold if the elasticity of substitution between labor and capital in the informal sector is greater than unity and where one of the urban formal sectors is characterized by the presence of a foreign owned factor of production. A positive shock to the informal sector through an effort to raise the productivity of workers, entreprenuerial skills, access to better technology or a credit subsidy to generate employment in the informal sector ${ }^{11}$ results in the terms of trade moving against labor, and ultimately culminating in a contraction of not only the informal sector but also the size of the urban formal sectors as well. At least in this regard, the informal-formal sector relationship is pro-cyclical: contraction of the informal sector causes a parallel contraction in one of the urban formal sectors while the other urban formal sector which uses an additional fixed factor (foreign capital) remains stagnant, irrespective of which of the urban formal sectors uses the informal sector output intensively.

While our analysis above underscores the conditions under which interventions in the informal sector can be harmful to an economy, the informal sector in developing economies plays a vital role in generating employment to a substantial segment of the population, particularly where employment opportunities in the formal sector is limited. In this respect, it is worth exploring existing evidence that points to the likelihood that the elasticity of substitution between labor and capital is indeed greater than one in the informal sector of developing countries. Unfortunately, empirical studies on the measurement of the elasticity of substitution between labor and capital in the informal sector of developing countries is rare primarily because of the difficulty in garnering reliable data from firms that self-select into this sector to avoid regulations and taxes, and also because of the difficulty in estimating capital stock since most machines

\footnotetext{
${ }^{10}$ Thus, $\hat{X}_{e}=\hat{L}_{e}, \hat{X}_{u}=\hat{L}_{u}$ and $\hat{X}_{r}=\hat{L}_{r}$.

${ }^{11}$ It can easily be checked that a credit subsidy to the informal sector will have the same effect on outputs and employment levels as long as the urban formal sectors are relatively more capital intensive, in the informal employment adjusted gross sense, than the rural sector. However, no condition need to be imposed on the elasticity of substitution as long as it is greater than zero. Also a credit subsidy to the informal sector reduces the return to capital there by an exact proportion to the subsidy. The return to capital in the other sectors remains unchanged.
} 
used in this sector are second-hand (Pack, 1976). Therefore, the best guess on the elasticity of substitution between labor and capital in the informal sector of developing countries has to be gleaned from either (i) empirical studies using data from manufacturing sectors, intermediate goods sectors and small scale manufacturing firms and/or (ii) theoretical studies or Computable General Equilibrium (CGE) models that use values of the elasticity of substitution between labor and capital based on available data from developing countries.

Some studies using econometric estimations of aggregate production functions in the manufacturing sectors show that the elasticity of substitution between capital and labor is considerable (Gaude, 1975). Pack (1976) in a study of the choice of techniques in Kenyan manufacturing firms found that the elasticity of substitution between labor and capital in the smaller manufacturing firms to be quite high. Yet, Pack observes that operators or managers favor a labor intensive technology simply because the wage rate is very low. Kalim (2001) analyzes specifications of the Constant Elasticity of Substitution (CES) production function to estimate the elasticity of substitution between capital and labor using cross-section data on 144 five-digit industries in Pakistan over the 1995-96 time period. Kalim finds that elasticity of substitution to be 1.62 for the intermediate goods industries which indicates a very strong effect of real wages on labor productivity. On the other hand, the size of the elasticity of substitution is 0.85 for the capital goods industries. Khan (2006) analyzes a four-sector (two formal and two informal) model where the formal sectors use skilled labor, unskilled labor and capital while the informal sector uses unskilled labor and capital and assumes elasticity of substitution values between these three factors to be between 0.8 and 2 to simulate the impact of poverty reduction strategies in South Asia. Finally, motivated by data gathered through household surveys in Argentina between 1993-1995, Amaral and Quintin (2004) describe a model where significant differences arise between formal and informal workers even though labor markets are perfectly competitive and show that, in equilibrium, the informal sector emphasizes low-skill work because informal managers have less access to outside financing, and as a result, choose to substitute low-skill labor for physical capital. The main theoretical assumption in Amaral and Quintin (2004) that fits empirical observations of informal sector activity in Argentina is based on the technological assumption that unskilled labor is a better substitute for physical capital than skilled labor.

Turning finally to policy implications of our study, it should be noted that the emergence, existence and expansion of the informal economy is in large part a response to regulations and taxes imposed on the formal sectors. To wit, Johnson, Kaufmann and Zoido-Lobaton (1998) 
find a positive correlation between the size of the informal economy and the corporate tax burden. Further, based on a survey of small firms in Brazil, de Paula and Scheinkman (2007), conclude that the choice of an entrepreneur to operate in the informal sector is driven by the motive to avoid taxes which formal sector firms are required to pay. Specifically, de Paula and Scheinkman show that in a vertically integrated production process, a credit system of value added taxes ${ }^{12}$ transmits informality along the production chain in the sense that the informality of a firm is positively correlated with the informality of the firms from which it buys and sells. However, when the credit system of a value added tax is replaced by a value added tax applied at any arbitrary stage of production, this chain effect on informality disappears.

In light of the analytics of this paper, we can conclude that taxes on the formal sector output, or a tax on the use of the informal sector output used by the formal sectors might lead to a contraction of the formal and informal sectors by first reducing input demand in the formal sector and subsequently in the informal sector due to the pro-cyclical nature of the relationship between the two. Likewise, a subsidy to capital used by the informal sector as well as policies that reduce the input-output coefficients in the informal sector directly ( such as, increased labor productivity, managerial skills or access to better technology) also leads to a contraction of the formal and informal sectors. In this latter respect, the contribution of our paper lies in identifying that technological improvements in the informal sector is harmful to economic growth in developing economies embarking on economic reforms through foreign capital-owned enterprises and characterized by forward linkages between the formal and informal sectors of the economy. Needless to say, identification of pro-growth policies through interventions in the formal or informal sectors of our model remains an agenda for future research.

\section{Appendix}

\section{Proof of proposition 1.}

Using equations (9), (10) and (11) along with Jones's (1965) hat calculus and the Wong-Viner Theorem, we get;

$$
\left[\begin{array}{ccc}
\theta_{K_{e}} & \theta_{x_{i}^{e}} & 0 \\
\theta_{K_{u}} & \theta_{x_{i}^{u}} & 0 \\
\theta_{K_{i}} & -1 & \theta_{L_{i}}
\end{array}\right]\left[\begin{array}{c}
\widehat{R} \\
\widehat{P}_{i} \\
\widehat{w}_{i}
\end{array}\right]=\left[\begin{array}{c}
0 \\
0 \\
-\hat{\beta}
\end{array}\right]
$$

Where $\theta$ 's suitably subscripted, denote the share of the input in the total income of an unit of

\footnotetext{
${ }^{12}$ Under this system the value added tax applies to each sale and each stage of production receives a credit for the amount of tax paid in the previous stages of the production stage.
} 
the commodity in question and $\mathcal{D}$, the determinant of the above matrix is denoted by,

$$
|\mathcal{D}|=\theta_{L_{i}}\left(\theta_{K_{e}} \theta_{x_{i}^{u}}-\theta_{K_{u}} \theta_{x_{i}^{e}}\right)>(<) 0
$$

We shall assume that $\hat{\beta}<0$, denoting technological improvement in the informal sector. Applying Cramer's rule:

$$
\frac{\widehat{R}}{\hat{\beta}}=\frac{\widehat{P}_{i}}{\hat{\beta}}=0
$$

and

$$
\frac{\widehat{w}_{i}}{\hat{\beta}}=-\frac{1}{\theta_{L_{i}}}<0
$$

Similarly using equations (8) and (12), we get;

$$
\left[\begin{array}{cc}
\theta_{L_{r}} & 0 \\
\frac{1}{\lambda} & -\frac{\bar{w}_{u}-w_{i}}{w_{r}}
\end{array}\right]\left[\begin{array}{c}
\widehat{w}_{r} \\
\hat{\lambda}
\end{array}\right]=\left[\begin{array}{c}
0 \\
\frac{1-\lambda}{\lambda} \frac{w_{i}}{w_{r}} \hat{w}_{i}
\end{array}\right]
$$

$\mathcal{R}$, the determinant of the matrix is given by,

$$
|\mathcal{R}|=-\theta_{L_{r}} \frac{\bar{w}_{u}-w_{i}}{w_{r}}<0
$$

Using Cramer's rule and substituting for $\widehat{w}_{i}$ from equation (13), we get,

$$
\begin{gathered}
\frac{\widehat{w}_{r}}{\hat{\beta}}=0 \\
\frac{\hat{\lambda}}{\hat{\beta}}=-\frac{\theta_{L_{r}}}{\theta_{L_{i}}} \frac{(1-\lambda)}{\lambda} \frac{w_{i}}{w_{r}} /|\mathcal{R}|>0
\end{gathered}
$$

Proof of proposition 2.

The cost minimization condition in the informal sector is;

$$
\theta_{L_{i}} \hat{a}_{L_{i}}+\theta_{K_{i}} \hat{a}_{K_{i}}=0
$$

Again,

$$
\hat{a}_{K_{i}}-\hat{a}_{L_{i}}=\sigma_{i}\left(\hat{w}_{i}-\hat{R}\right) .
$$

Manipulating the above two equations we get,

$$
\begin{gathered}
\hat{a}_{L_{i}}=-\theta_{K_{i}} \sigma_{i}\left(\frac{\hat{w}_{i}}{\hat{\beta}}-\frac{\hat{R}}{\hat{\beta}}\right) \hat{\beta}+\hat{\beta} . \\
\hat{a}_{K_{i}}=\theta_{L_{i}} \sigma_{i}\left(\frac{\hat{w}_{i}}{\hat{\beta}}-\frac{\hat{R}}{\hat{\beta}}\right) \hat{\beta}+\hat{\beta} .
\end{gathered}
$$


Using equations (5), (6), (7), the fact that demand for foreign capital equals its fixed supply, the definition of $\lambda$ and substituting for $\hat{a}_{L_{i}}$ and $\hat{a}_{K_{i}}$ from equations (15) and (16) we get,

$$
\begin{aligned}
& {\left[\begin{array}{cccc}
0 & K_{f} & 0 & 0 \\
0 & 0 & (1-\lambda) L_{r} & L_{i} \\
x_{i}^{u} & x_{i}^{e} & 0 & -1 \\
K_{u} & K_{e} & K_{r} & K_{i}
\end{array}\right]\left[\begin{array}{c}
\widehat{X}_{u} \\
\widehat{X}_{e} \\
\widehat{X}_{r} \\
\widehat{X}_{i}
\end{array}\right]=\left[\begin{array}{c}
\mathcal{K}_{f} \hat{\mathcal{K}}_{f} \\
-\left\{\left(L_{u}+L_{e}\right) \hat{\hat{\lambda}}+L_{i}\left(\frac{\theta_{K_{i}}}{\theta_{L_{i}}} \sigma_{i}+1\right)\right\} \hat{\beta}+(1-\lambda) \mathcal{L} \hat{\mathcal{L}} \\
0 \\
\mathcal{K} \hat{\mathcal{K}}-K_{i}\left(1-\sigma_{i}\right) \hat{\beta}
\end{array}\right]} \\
& |\mathcal{H}|=-K_{f} x_{i}^{u} L_{i} L_{r}\left\{k_{r}-(1-\lambda) \frac{x_{i}^{u} K_{i}+K_{u}}{x_{i}^{u} L_{i}}\right\}>(<) 0 .
\end{aligned}
$$

Let us denote

$$
\left\{\left(L_{u}+L_{e}\right) \frac{\hat{\lambda}}{\hat{\beta}}+L_{i}\left(\frac{\theta_{K_{i}}}{\theta_{L_{i}}} \sigma_{i}+1\right)\right\}=M>0 .
$$

Assuming that the urban formal sectors are relatively more capital intensive, in the informal employment adjusted gross sense, than the rural sector and applying Cramer's rule to the output matrix yields,

$\frac{\widehat{X}_{u}}{\hat{\beta}}=-K_{f} L_{r}\left\{K_{i}\left(1-\sigma_{i}\right)(1-\lambda)-M k_{r}\right\} /|\mathcal{H}|>0$ if and only if $\sigma_{i}>1$.

$\frac{\widehat{X}_{e}}{\hat{\beta}}=0$

$\frac{\widehat{X}_{r}}{\hat{\beta}}=-K_{f}\left\{\left(K_{u}+x_{i}^{u} K_{i}\right) M-K_{i} L_{i}\left(1-\sigma_{i}\right)\right\} /|\mathcal{H}|<0$ if and only if $\sigma_{i}>1$.

$\frac{\widehat{X}_{i}}{\hat{\beta}}=-K_{f} x_{i}^{u} L_{r}\left\{K_{i}\left(1-\sigma_{i}\right)(1-\lambda)-M k_{r}\right\} /|\mathcal{H}|>0$ if and only if $\sigma_{i}>1$.

However, for output of the domestic urban formal sector and the informal sector to increase and the output of the rural sector to decrease a necessary but not a sufficient condition is that the elasticity of substitution between labor and capital in the informal sector is less than unity. The urban sectors will expand and the rural sector will contract only if $\sigma_{i}<1$ and if $K_{i}\left(1-\sigma_{i}\right)(1-\lambda)>M k_{r}$ and $K_{i} L_{i}\left(1-\sigma_{i}\right)>\left(K_{u}+x_{i}^{u} K_{i}\right) M$.

\section{Proof of proposition 3}

To show that employment in the informal sector falls consider the following equation:

$$
\frac{\widehat{L}_{i}}{\hat{\beta}}=\left(\frac{\theta_{K_{i}}}{\theta_{L_{i}}} \sigma_{i}+1\right)+\frac{\widehat{X}_{i}}{\hat{\beta}}
$$


Employment in the informal sector falls as the second term on the right hand side of the above equation reinforces the first term. 


\section{References}

Amaral, Pedro and Erwan Quintin (2006); "The Implications of Capital-Skill Complementarity in Economies with Large Informal Sectors", Journal of Monetary Economics, 53, pp 1541-1553.

Chandra, V and M. Ali Khan. (1993); "Foreign Investment in the Presence of an Informal Sector", Economica, 60, pp 79-103.

Chen, Martha. (2006); "Rethinking the Informal Economy: Linkages with the Formal Economy and the Formal Regulatory Environment", in Guha-Khasnobis, B., Kanbur, R. and Ostrom, E. (eds) Linking the Formal and Informal Economy: Concepts and Policies, WIDER Studies in Development Economics, Helsinki. pp 75-93.

de Paula, Aureo and Jose Scheinkman (2007); "The Informal Sector", Penn Institute for Economic Research working paper No. 07-035. Department of Economics, University of Pennsylvania, Philadelphia, PA.

Chaudhuri, Sarbajit and Shigemi Yabuuchi. (2007); "Economic Liberalization and Wage Inequality in the presence of Labour Market Imperfection"; International Journal of Economics 83 Finance, 16, pp $592-603$.

De Soto, Hernando. (1989); The Other Path: The Invisible Revolution in the Third World, Harper and Row, New York.

Dutta-Choudhuri, T. (1989); "A Theoretical Analysis of the Informal Sector", World Development, 17, pp $351-355$.

Fields, Gary. (1975); "Rural-Urban Migration, Urban Unemployment and Underemployment, and Job Search Activity in LDCs" Journal of Development Economics, 2, pp 165-187.

Gaude, J (1975); "Capital-Labour Substitution Possibilities: A Review of the Empirical Evidence," in Technology and Employment in Industry, A. S. Bhalla (ed), International Labour Organisation, Geneva.

Guha-Khasnobis, B., Kanbur, R. and Ostrom, E. (eds). (2006); Linking the Formal and Informal Economy: Concepts and Policies, WIDER Studies in Development Economics, Helsinki.

Harris, J.R. and Todaro, M.P. (1970); "Migration, Unemployment and Development: A Two Sector Analysis", American Economic Review, 60, pp 126-142.

Johnson, Simon; Daniel Kaufmann and Pablo Zoido-Lobaton (1999); "Corruption, Public Finances, and the Unofficial Economy", Policy Research Working Paper Series 2169, The World Bank, Washington D.C.

Jones, R.W. (1965); "The Structure of Simple General Equilibrium Models", Journal of Political Economy, 73 , pp 557-572.

Kalim , Rukhsana (2001), "A Measure of the Elasticity of Substitution in the Manufacturing Sector of Pakistan", The Lahore Journal of Economics, 6, pp 43-57. 
Khan, Haider A (2006); "Macro-Modeling of Poverty and the Dual-Dual Model", in Haider A. Khan and John Weiss (eds), Poverty Strategies in Asia: A Growth Plus Approach, Edward Elgar Publishing, Northampton, MA, USA.

Liimatainen, Marjo-Riitta. (2002); Training and Skills Acquisition in the Informal Sector: A Literature Review, InFocus Programme on Skills, Knowledge and Employability, International Labour Office, Geneva.

Marjit, Sugata. (2003). "Economic Reform and Informal Wage - A General Equilibrium Analysis", Journal of Development Economics, 72, pp 371-378.

Marjit, Sugata, Saibal Kar and Hamid Beladi (2007). "Trade Reform and Informal Wages", Review of Development Economics, 11, pp 313-320.

Pack, Howard (1976); "The Substitution of Labour for Capital in Kenyan Manufacturing"; The Economic Journal, 86, pp. 45-58.

Portes, Alejandro, Castells, M and Benton, L. (eds). (1989); The Informal Economy: Studies in Advanced and Less Developed Countries. Baltimore: Johns Hopkins University Press.

Portes, Alejandro and Richard Schauffler (1993); "Competing Perspectives on the Latin American Informal Sector", Population and Development Review, 19, pp 33-60.

Roy, Malabika. (2006); "Effect of Subsidy and Entry into the Informal Sector with Interlinkage"; International Review of Economics \& Finance; 15, pp 383-397.

Schneider, Friedrich and Robert Klinglmair (2004); "Shadow Economies around the World: What do we Know?", Working Paper No. 0403, Department of Economics , Johannes Kepler University, Linz, Austria. 